\title{
Analysis and Development of Land Information System of Bauchi State soil types capabilities in Enhancing Crop Production
}

\author{
${ }^{1}$ M. A. Modibbo, ${ }^{2}$ Y. L. Sumi \\ ${ }^{1 \& 2}$ Department of Surveying and Geoinformatics, Abubakar Tafawa Balewa University Bauchi, Bauchi State
}

\begin{abstract}
This research paper is focused on the analysis and development of a land information system for the different soil types in Bauchi State and their capabilities in enhanced crop productivity, which covers the whole of Bauchi State .the execution of this project, was carried out in two different stages namely: The design stage and the implementation stage. The development of the LIS was facilitated by obtaining a clear and properly identified map of the study area, which was eventually scanned and saved in JPEG format. The scanned map was further geo-referenced and digitized on software and exported to the ARCVIEW GIS9.3 software. The graphics were linked with a created spatial database; the developed system was then put to the test by carrying out a number of GIS operation and analysis called queries (Kufoniyi, 1998). The queries were then generated to help in the identification and differentiation of the various soil types existing in Bauchi as well as their capabilities as regards to the types of crops planted in Bauchi state in other to device means for which production can further be enhanced.
\end{abstract}

Key words: LIS, GIS, Queries

\section{Introduction}

Land is the most valuable possession of any country as it is known to be a source of material wealth. It is from land that we derive anything of value, be it food, clothing, shelter or other natural resources. The availability of land alone human existence itself as it is the medium through which man gets to feed for survival as he tills the soil for farm produce. It is therefore apparent that any information concerning land is valuable as it serves as a key to financial investments, commerce, industry and agriculture. The classification is however based on certain assumptions which must be understood by anyone using a soil capability map and statistical data derived from these maps (Ariola, 1999). Similarly, it is not a guide to the most profitable use of land but it serves as an inventory for agricultural soil resources and a guide to better land usage. One of the most efficient method of achieving the aim and objective of this research is by taking and integrating the various soil types and crop types into one system as a unified database, this in essence is referred to as land information system.

Land property rights had to be installed leading initially to the establishment of national cadastral services and in a second stage, land becomes an object of taxation. Simultaneously, this created a growing need for a better knowledge of the soils and of their production potential (Dale and McLaughlin, 1999). The basis of land information system is a uniform spatial referencing system for the data in the system which also facilitates the linking of data within the system with other land related data. A land information system for the enhancement of crop productivity for the various soil types and their capability in Bauchi State will consist of components such as: A complete database, a software system and the functional operating process, human resources and technical ability. For a long time, land and land related issues were directly related to agricultural or livestock production, assessment of quality of land or practices to improve such qualities remained a matter of local rural expertise. Land was considered a natural free gift available to all members of the clan. As long as the population was small in number, the competition for land remained relatively small; exceptions to these natural rules occurred in cases where a local group wanted to expand power and went to war with its neighbor's (Olayele, 1999).

The objective of this study is to provide database that will enhance information collection, storage, manipulation, dissemination and retrieval of information within short time. To create link between different types of soil that existing within the state and crops planted on them to aid to identify what, when and it is suitable to plant such crops.

\section{The need for land/soil analysis}

The amount of cultivable land in the world is finite, and land that has been degraded is almost irreversibly lost for production. As long as the populations who use this land remain small in number, they are able to live in harmony with their natural environment. The pressing demand for food and space from a growing population has created a competition for land. The best suitable land is already short in supply and even less suitable, viz marginal areas, gradually taken into cultivation. In many developing countries, fuel wood, cash crops, timber for construction and grazing for livestock compete with food crops for space, not only on the 
better quality land but also on the degradation through loss of plant nutrients and organic matter, erosion, buildup of salinity and damage to soil structure. In the industrialized world the demand for more food has led to an intensification of agriculture. At present, the importance of soil analysis and ultimately land use planning should be seen in the context of land becoming a scares and non-renewable natural resource which is highly desired, for which there is a growing competition and which obviously, holds a proper exchange value. It is moreover linked to a situation whereby decision to change the use of land may have a large influence on social attitudes and on the society as a whole. Agriculture is often seen as an environmental problem but if carefully managed, it can also become an integral part of the environment. If good quality indicators are used to monitor the impact of agriculture or any other land use activity then decisions to change or enhance might be evident.

Preliminary investigation revealed that the efforts has been made by the federal government of Nigeria at her level to implement land information system but only about $20 \%$ of the states in Nigeria have commenced the application of ICT in their land administration talk less of in agricultural practice. Ironically, among those states that have initiated land records computerization, the extent, content and compatibility of the programme are not easily ascertained because there is little or no central coordination and monitoring. Although there is a national geospatial data infrastructure (NGDI) policy document, the implementation and testing is not yet widespread. So far what exists are isolated land record management system established by some state governments and which are yet to be brought into a national network to entrench seamless integration and data sharing/exchange among the states. The national air space development agency (NASDA) where the committee on spatial data infrastructure domiciled is working to produce data that could be shared among various land data users across the country

\section{Brief description of study area}

The present Bauchi States southern and northern limits are demarcated by latitudes $9^{\circ} 30^{\prime}$ North and $12^{\circ} 30^{\prime}$ North respectively it is western and eastern limits are bounded by longitudes $8^{\circ} 45^{\prime}$ East and $11^{\circ} 0^{\prime}$ East respectively. Therefore this marks the points of longest and widest stretches of the state. Within these coordinates, the state assumes a distinct figure with a blotted lower region, with about two thirds of the land area being south of latitude $11^{\circ} 15^{\prime} \mathrm{N}$. The study area, Bauchi state is located in the North-Eastern part of Nigeria as shown in the fig. 1 below:

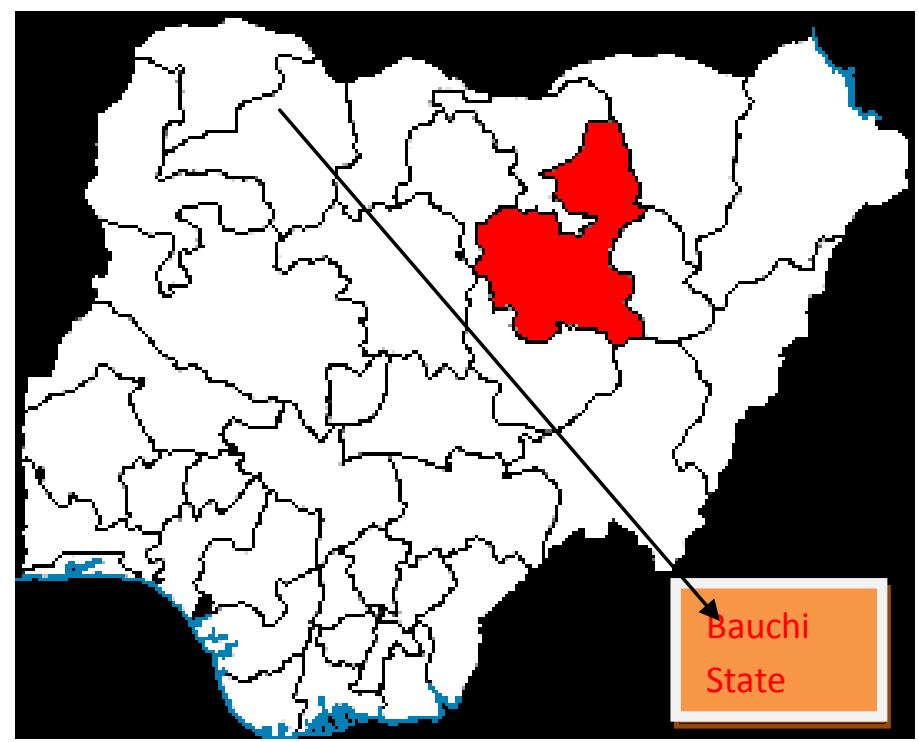

Fig 1: Map of Nigeria showing the location of Bauchi state

III. Geological and soil composition

Bauchi is basically composed of crystalline rocks, in Nigeria basement complex mostly Precambrian to the early Paleolithic in age. The rocks include the mixture of granites, gneisses, pegmatite and some amount of charnokite at the margin around the area. Granites are coarse grained and are composed of quartz, alkali, feldspar, biotite and muscouite with ancestry horn bled and haematite. Pegmatite veins nwithin the gneisess are composed of potash feldspar and very large crystal may form. A charnokiti rock occurs around the margin where it forms small out crops. Bauchi metropolis lies within the undifferentiated basement complex with older granites outcrops and young granites out crops. The basement complex isbest described as crystalline rocks of the area.It is also made up of shallow soilsuch as sandy, clay, and loamy soil in iron pan, underlined by crystalline rocks, hills, mountains, which consists of rock elements on slope of hills and mountains. 


\section{Methodology}

The methodology in this study involved the acquisition of the Bauchi State soil map which was scanned and geo-referenced for the purpose of defining its existence in physical space as the map of Bauchi State soils and its local government were overlaid and superimposed.

\subsection{Source of data}

\subsection{Primary source}

These are data that are being generated by either taking direct measurements on the field, issuing of questionnaires, interviewing, focus groups discussions or observation of the participants. in this context, the information gathered were by a one on one interview with agriculture experts at the BSADP from whence these information were obtained.

\subsection{Secondary source}

This is a kind of data that was not primarily obtained for the purpose of its present usage. It is usually collected by someone or through someone else or agencies for a more general purpose and quite often distinct from the main objective of the users as some of this information are seen to be classified .Examples of such data include books, journals, reports, registers, maps, photographs, and satellite imageries. The secondary data used in this project was a map collected from the ministry of lands in Bauchi State as directed by the former surveyor general of the state to enable the execution of this project.

\section{Analysis and presentation of results}

The spatial analysis reveals underlying trend in geographic data and this make new information available for use. The analysis that has been performed on this project further reveals that LIS is a powerful tool for the management of soil, its capabilities, and how it supports the growth of certain crops within Bauchi State. It also serves as a medium for storage of files and information that could be subject to loss or damage. Based on this analysis carried out, the results will aid in the provision of easy orientation and enlightenment seminars to farmers for an improved or enhanced crop yield. When GIS analysis is properly utilized, productivity can be enhanced and data security will also be ensured. Therefore the management is easily monitored.

\subsection{Database design}

\section{Database design and implementation}

Database design refers to the process of defining or representing the features to be included in a database, together with their attributes and successive relationships. This was however done in different stages which includes; View of reality, Conceptual design, Logical design and Physical design.

\subsection{Data implementation}

The data was captured by scanning the existing soil map of Bauchi State using an A0 scanner. The scanned map was then saved in a JPEG file format. The state boundaries were then captured through a coordinate system and geo-referencing using the ArcGIS 9.3 software, thereby extracting the boundary layers within the local government area map was superimposed on the base map. The digitized map was then exported to ArcGIS 9.3 software for further analysis.

\subsection{Querying}

This is one of the outstanding capabilities of the Geographical Information System; it is function to assign value to each targeted feature and to separate features of interest based on their individual attributes. The purpose for these is to ease the retrieval of information about features or entities on the digitized map. The queries however used were carried out based on the designed and created database.

\subsection{Data presentation technique}

Data presentation was done in ArcGIS 9.3 environment by selecting in other to access any data for presentation e.g.; a farmer from a particular location within the state may be interested in knowing the soil type present in his LGA and the crops that can be grown on them, the following steps to be followed to achieve result display are as follows:

1. Click on selection on the toolbar $\rightarrow$ selection by attributes.

2. Double-click on LGA $\rightarrow$ equal sign $\rightarrow$ get unique values (list of LGA within Bauchi is generated) $\rightarrow$ double-click on Alkaleri $\rightarrow$ apply.

3. On the table of content, right-click on SOIL_TYPE $\rightarrow$ open attribute table $\rightarrow$ options $\rightarrow$ report $\rightarrow$ create report (a generating wizard uploads).

4. On the available fields; click on the field needed to add to the report field $\rightarrow$ generate report. 
5. A report viewer comes up showing the report of the selected fields as shown below;

Hence, the farmer maybe asked questions on what type of crop he/she intends growing? On any choice of crop he makes; the report generated will be checked to locate a soil type on which the crop he chose is best grown. Once the soil type is identified, a query is carried out to locate where that particular soil type can be found through the following steps :( supposing the LGA is Alkaleri)

1. Click on selection on the toolbar $\rightarrow$ selection by attributes.

2. Double-click on LGA $\rightarrow$ equal sign $\rightarrow$ get unique values $\rightarrow$ double-click on Alkaleri $\rightarrow$ and $\rightarrow$ doubleclick on SOIL_TYPE $\rightarrow$ equal sign $\rightarrow$ get unique values $\rightarrow$ double-click on shallow to deep soils on sandstones $\rightarrow$ apply $\rightarrow$ ok.

3. On the table of content, right-click on SOIL_TYPE $\rightarrow$ properties $\rightarrow$ symbology $\rightarrow$ features $\rightarrow$ apply $\rightarrow$ ok.

4. On the table of content, click on the color symbol below the SOIL_TYPE $\rightarrow$ fill colour $\rightarrow$ no colour $\rightarrow$ ok.

5. On the table of content, mark the project raster to upload the base map.

6. On the map frame, right-click $\rightarrow$ zoom to selected feature (shows the village yalo of Alkaleri LGA).

7. To obtain the coordinates of the selected feature: right-click on the map frame $\rightarrow$ identify (all information about the selected feature is shown).

With the above steps followed properly, the farmer can therefore be advised and informed appropriately.

\section{Conclusion}

The application of modern technology is quite helpful in land usage; the basic purpose is to provide transparent standardized and easily accessible information. A modeled database for the soil Capability for Agriculture has been developed to show the agricultural potential of land based on the degree of limitation imposed by its biophysical properties. It is based primarily on climate, a number of soil properties, (for example depth and stoniness), wetness, erosion risk and slope.

\section{Recommendation}

It is recommended that Bauchi State should implement the application of the land information system in its agricultural production through the orientation and enlightenment programme which will help in solving the question on what, when and where to plant certain crops in order to achieve the best of results for both commercial and human consumption. This would further help in an effective sourcing of revenue for the government as Soil surveys continue to provide a wealth of useful reference material regarding local soil conditions. The information on soil capability or crop yield potential of various soil series is not, however, valid for today's crop production technology other than as a relative guide to compare different soil types. There should also be a medium to which encouragements and assistance are given to higher institutions for the establishments of GIS dependency.

\section{References}

[1]. Ariola, L. L. (1999); Digital Cadastral Survey and it is Potential for Revenue Generation. Paper presented at the survey coordination and advisory board of survey training conference Akure.

[2]. Dale, P. F and John D. M. (1999); Land Information Management; An introduction with special reference to cadastral problems in third world countries Clarendon press, London.

[3]. Olayele, J. B. (1999); Concept of multipurpose cadaster, in Ezeigo C. U. (ed) Principle and Application of Geographical Information System, Lagos Nigeria.

[4]. Kufoniyi, O. (1998); Database design and creation, First edition, Panat press, Lagos, Nigeria 